\title{
Ameliyat sırası hava yolu tıkanıklığının beklenmeyen nedeni: Trakeotomi kanülünün deforme balonu
}

\author{
Unpredictable cause of intraoperative airway obstruction: \\ Malformed cuff of tracheotomy tube \\ Fatma Çaylaklı1(1) Esra Çalışkan (102 ${ }^{2}$ \\ ${ }^{1}$ Başkent Üniversitesi Tip Fakültesi, Kulak Burun Boğaz Anabilim Dalı, Ankara, Türkiye \\ ${ }^{2}$ Başkent Üniversitesi Tip Fakültesi, Anesteziyoloji ve Reanimasyon Anabilim Dall, Ankara, Türkiye
}

\section{$\ddot{O} Z$}

Trakeotomi, hava yolu açıklığı için trakeanın ön duvarında delik açılan cerrahi bir işlemdir. Trakeotomi sırasında ve sonrasında komplikasyonlarla karşılaşılabilir. Bu yazıda, trakeotomi sırasında trakeotomi kanülünün deforme balonuna bağlı gelişen havayolu tıkanıklığı tartışıldı.

Anahtar sözcükler: Komplikasyon; ameliyat sırası; deforme balon; trakeotomi.

Trakeotomi, hava yolu açıklığ 1 için cerrahi yöntemle trakeanın ön duvarında bir delik açma işlemidir. En az 3000 yıldır bilinmekte ve kelime olarak Yunancadan köken almaktadır. ${ }^{[1,2]}$ Günümüzde yoğun bakım ünitelerindeki gelişmeler ve yaygin olarak mekanik ventilatörlerin kullanılmasindan dolayı trakeotomi en sik uygulanan cerrahi girişimlerden biridir. Havayolu direncini azaltarak ventilatuar kapasitesi az olan hastalarda düzgün solunuma geçişi hızlandırmaktadır. Cerrahi işlem sırasında ve sonrasında komplikasyonlarla karşılaşılabilir. Bu yazıda trakeotomi sırasında trakeotomi kanülüne bağlı havayolu tıkanıklığı yaşanan bir olgu sunuldu.

\section{OLGU SUNUMU}

Altmış beş yaşında kadın hasta ses kısıklığı ve solunum zorluğu yakınması ile kliniğimize başvurdu.

\begin{abstract}
Tracheotomy is a surgical procedure that involves opening a hole in anterior wall of trachea for airway clearance. We may experience complications during and after tracheotomy. In this article, we discussed airway obstruction due to malformed cuff of tracheotomy tube during tracheotomy.
\end{abstract}

Keywords: Complication; intraoperative; malformed cuff; tracheotomy.

Fizik muayenesinde sağ hemilarenksi tutan, hava yolunu daraltan ve sağ vokal kord paralizisi olan larengeal vegetan kitle tespit edildi. Bu bulgularla direkt larengoskopi eşliğinde biyopsi ve trakeotomi açılması planlandı. Ameliyathanede hastaya sedoaneljezi ve lokal anestezi eşliğinde trakeotomi açıldı, trakeotomi kanülü yerleştirildi ve genel anesteziye geçilerek ameliyata devam edildi. Kisa bir süre sonra, hastanın oksijen satürasyonunun düşmesiyle birlikte her iki hemitoraksının da havalanmadığ1 görüldü. Havayolundan emin olmak için aspiratör sondası kanül içinden geçirildi, zorla da olsa kanül içinden geçtiği gözlendi. Hastanın buna rağmen ventile edilememesi üzerine pnömotoraks olasılığ düşünüldü. Pnömotorakstan emin olunamadi, ancak trakeotomi kanülü içerisinden zorla da olsa aspiratör sondasının geçişi gözlemlendiği için üst hava yolunun açık olduğu varsayıld. Durumun ciddiyeti açısından pnömotoraks 


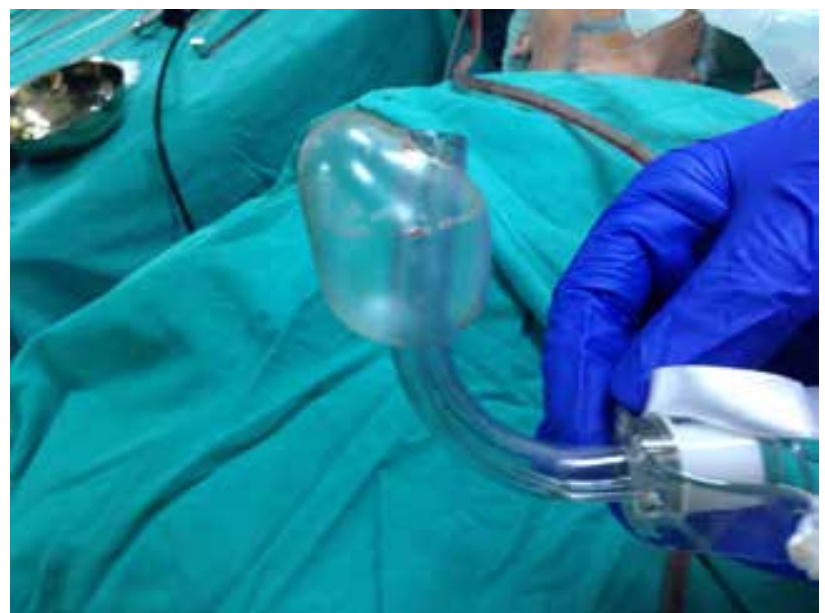

Şekil 1. Deforme balonlu trakeotomi kanülü.

olabileceği varsayılarak sağ akciğgere göğüs tüpü yerleştirildi. Ancak tüm bu müdahalelere rağmen akciğer havalanmasının gözlenmemesi üzerine kanülde sorun olabileceği düşülerek kanül yerinden çıkartıldı ve entübasyon tüpü ile açılan trakeotomi yerinden entübe edildi ve havalanma sağlandı. Ardından direkt larengoskopi eşliğinde larengeal biyopsi uygulandı, trakeotomi yeri açık bırakıldı. Ameliyat komplikasyonsuz sonlandırıldı. Ameliyat tamamlandiktan sonra traketomi kanülü değerlendirildi ve balonunun deforme olduğu fark edildi (Şekil 1). Balon şişirildiğinde, trakeotomi kanülü trakea içinde iken, balonun kanülün ağzını tıkadığı dolayısıyla hava yolunu da tıkadığı gözlendi.

\section{TARTIŞMA}

Trakeotomi komplikasyonlarını ameliyat sırası (erken), orta (erken ameliyat sonrası) ve geç (geç ameliyat sonrası) olarak sinıflayabiliriz. Bu sınıflamayı cerrahi işlemden komplikasyon gelişene kadar geçen süreye göre yapmaktayız (Tablo 1). ${ }^{[1,2]}$ Yapılan birçok retrospektif çalışmada komplikasyon oranları \%5'ten \%40'a kadar değişkenlik göstermektedir. ${ }^{[3]}$ En sık görülen komplikasyon kanamadır (\%3.7), bunu tüp obstrüksiyonu (\%2.7) ve tüp yer değiştirmesi (\%1.5) izlemektedir. Daha az görülen pnömotoraks, trakea darlığı ve trakeaözofageal fistül insidansı \%1'den azdır. Ölüm, sıklıkla kanama ve tüpün yer değiştirmesine bağlı olarak görülebilir ve oranı \%0.5 ila \%1.6 arasındadır. Acil trakeotomilerde komplikasyon görülme insidansı elektif trakeotomilere göre 2-5 kat daha fazladır. ${ }^{[1-5]}$ Bizim olgumuzda ameliyat sırası havayolu tıkanıklığ 1 yaşandı ve buna da trakeotomi kanülünün deforme balonu neden oldu. Literatürde bahsedilen komplikasyonlar cerrahi işleme bağlı yaşanan komplikasyonlardır. Ameliyat sırası hava yolu tıkanıklığının trakeotomi kanülüne bağlı olabileceği pek akla

\begin{tabular}{|l|}
\multicolumn{1}{c|}{ Tablo 1 } \\
Trakeotomi komplikasyonları \\
\hline Ameliyat sırası (erken) \\
Kanama-ameliyat sırası \\
Trakeotomi kanülünün yanlı̧̧ bir rotaya yerleştirilmesi \\
Hava embolisi \\
Apne \\
Çevre dokulara cerrahi hasar verilmesi \\
Ameliyat sırası yanık \\
Erken ameliyat sonrası (orta) \\
Kanama-ameliyat sonrası \\
Trakeotomi kanülünün yer değiştirmesi/tıkanması \\
Subkütan anfizem, pnömotoraks, pnömomediastinum \\
Enfeksiyon \\
Geç ameliyat sonrası (geç) \\
Kanama-granülasyon dokusunun traksiyonu, \\
trakeoinnominat arterin erozyonu \\
Trakeal darlık, subglottik darlık \\
Trakeokütanöz fistül \\
Trakeoözofageal fistül \\
\hline
\end{tabular}

gelmemektedir. Literatürde trakeotomi kanülünün doğru yerleştirilememesine ve kanüle bağl1 üst hava yolu tıkanıklı̆g1 olguları nadir olarak sunulmuştur. ${ }^{[6,7]}$ Böyle bir komplikasyonun önüne geçmek için cerrahın kendisinin balonu şişirerek olası deformasyonu gözden kaçırmamasını öneririz. İşlem sırasında hava yolunun açıklı̆̆ından emin olmak için aspiratör sondasını trakeotomi kanülü içerisinden geçirdigimizde kanül içinden zorla geçtiğini gözlemledik. Böyle bir durumda kanüle bağlı bir sorun olabileceğini düşünerek kanülün değiştirilmesini öneriyoruz.

\section{Çıkar çakışması beyanı}

Yazarlar bu yazının hazırlanması ve yayınlanması aşamasında herhangi bir çıkar çakışması olmadı̆̆ını beyan etmişlerdir.

\section{Finansman}

Yazarlar bu yazının araştırma ve yazarlık sürecinde herhangi bir finansal destek almadıklarını beyan etmişlerdir.

\section{KAYNAKLAR}

1. Goldenberg D, Bhatti N. Erişkinlerde yetersiz hava yolunun kontrolü. In: Cummings CW, Flint PW, Haughery BH, Robbins KT, Thomas JR, Harker LA, editors. Cummings Otolaringoloji-Baş ve Boyun Cerrahisi. 4. Baskı. Elsevier Mosby; 2007. p. 2441-53.

2. Goldenberg D, Ari EG, Golz A, Danino J, Netzer A, Joachims HZ. Tracheotomy complications: a retrospective 
study of 1130 cases. Otolaryngol Head Neck Surg 2000;123:495-500.

3. Waldron J, Padgham ND, Hurley SE. Complications of emergency and elective tracheostomy: a retrospective study of 150 consecutive cases. Ann R Coll Surg Engl 1990;72:218-20.

4. Myers EN, Carrau RL. Early complications of tracheotomy. Incidence and management. Clin Chest Med 1991;12:589-95.

5. Halum SL, TingJY, Plowman EK, Belafsky PC, Harbarger CF, Postma GN, et al. A multi-institutional analysis of tracheotomy complications. Laryngoscope 2012;122:38-45.

6. Lois M, Oltermann M. Tracheal obstruction as a complication of tracheostomy tube malfunction: case report and review of the literature. J Bronchology Interv Pulmonol 2010;17:253-7.

7. Abola RE, Tan J, Wallach D, Kier C, Seidman PA, Tobias JD. Intraoperative airway obstruction related to tracheostomy tube malposition in a patient with achondroplasia and Jeune's syndrome. Middle East J Anaesthesiol 2010;20:735-8. 